\title{
Research on Enterprise Management Innovation in the Era of "Internet Accelerated Speed Era"
}

\author{
Yuan $\mathrm{Ma}^{1, \mathrm{a}}$ \\ ${ }^{1}$ Nanyang Institute of Technology \\ Nanyang, Henan, 473004
}

\begin{abstract}
Since China put forward the "Internet Accelerated Speed Era" strategy in 2012, "Internet Accelerated Speed Era" has been integrated into all walks of life and various fields, making China enter the Internet era. Because the Internet is very open and integrated, it also provides a historic opportunity for enterprise management. Under the strategy of "Internet Accelerated Speed Era", to the enterprise management work put forward higher request, must vigorously promote the optimization and perfection of the enterprise management mode, especially enterprise must realize that the age of the Internet enterprise value management innovation, analyzes the factors restricting the age of the Internet enterprise management innovation, using the system thinking and innovative concept, vigorously promote reform, innovation and development of enterprise management, try to make the enterprise management work to a new level.
\end{abstract}

Keywords-Internet Accelerated Speed Era; Enterprise management; Innovation

\section{INTRODUCTION}

"Internet Accelerated Speed Era" comes into being in the 2.0 Internet innovation mode. It is a new form of economic and social development that rises under the background of knowledge social innovation 2.0. "Internet Accelerated Speed Era" is the practical result of Internet thinking mode, which promotes the reform of modern economic form and provides high-end network technology for Chinese enterprises in the process of innovation, reform and development. From a general point of view, "Internet Accelerated Speed Era" means the "Internet" with the traditional industry integration, but is not a simple list and joining together, but by information technology and Internet system, make the Internet fully combine the advantages of traditional industries and characteristics of the two in-depth integration, network services in modern enterprises, contribute to promote the process of socialist development. It represents a new form of social productivity, which make full use of the Internet in the allocation of social resources and advantages and integration, the Internet technology innovations into in the sequence of the market economy, improve the innovation mechanism, make the social productive forces reached the highest state of operation, the formation of more intensive Internet foundation, the construction of a new economic development pattern.

As a comprehensive working system, enterprise human resource management involves multiple aspects and channels, runs through the whole process of enterprise operation, and affects the present and future development mode of enterprises.
The application mode of Internet technology in enterprise human resource management provides convenient conditions for human resource management and puts forward higher requirements for modern enterprises. Integration is a basic feature of the "Internet Accelerated Speed Era" era. Corporate human resource managers can use Internet software to carry out management work, which can save labor and greatly improve work efficiency. Such as human resource managers can through the App and other media to convey orders, announced that the installation of the enterprise employees through the App can also learn about enterprise dynamic real-time field, establish work interaction relationship, enhance the cohesion between the with the enterprise, so as to improve the market competitiveness of enterprises, the road lay the foundation for the innovation of the modern enterprise.

\section{THE SIGNIFICANCE OF HUMAN RESOURCE MANAGEMENT FOR ENTERPRISE DEVELOPMENT IN THE ERA OF "INTERNET ACCELERATED SPEED ERA"}

With the advent of the Internet era, people's life style has been changed, providing great convenience for people's life. In the operation process of enterprise human resource management, the Internet provides a large amount of information and resources for the human resource system.

First of all, as an important content of human resource management, recruitment mode in traditional enterprise recruitment mode, the enterprise through radio, radio, print and other forms to release recruitment information, "Internet Accelerated Speed Era" in modern times, the human resources department rely on relevant websites, online media, such as release recruitment information, also can change at any time from the aspects of the demand of the enterprise dynamic and information, operation more convenient, make the person be clear at a glance, facilitate communication and reading.

In addition, as an important project in human resource management, education and training requires oral notification of tasks, contents, time and location of training in the traditional training mode [1]. Such a notification model has been very slow, time-consuming and laborious, a huge waste of manpower and financial resources, reducing work efficiency. Under the background of "Internet Accelerated Speed Era" era, the enterprise education and training is not limited by time and space, and constraints, can the establishment of the education and training through the network platform, the human resources department by uploading method to implement the training materials, resources in the form of having a unique 
style, variety, such as text, video, pictures, music, animation and so on many patterns, enterprise employees can download data anytime and anywhere through the way to enrich their professional knowledge, so as to improve their professional skills in the end, in the "Internet Accelerated Speed Era" era, enterprise human resources department can through to the personnel to implement systematic job scheduling and control, It enables employees to smoothly enter, transfer and leave their posts, highlighting the advantages of modern technology and promoting the work process of human resources department.

In short, the rise of "Internet Accelerated Speed Era" technology has changed people's way of life and brought more innovative modes and challenges to enterprises' tourism projects. Therefore, human resource management departments should seek development through innovation, fully understand the domestic and foreign trends, grasp the pulse of The Times and achieve the development goals of enterprises. The innovation of "Internet Accelerated Speed Era" technology mode has clarified the direction of enterprise human resource management.

\section{CONSTRAINTS ON ENTERPRISE MANAGEMENT INNOVATION IN THE ERA OF "INTERNET ACCELERATED SPEED ERA"}

\section{A. The platform system is not perfect}

In the Internet era, the enterprise management mode has undergone profound changes, and the traditional "offline" management mode is restricted. It is required to vigorously promote the network construction, or it will restrict the effective development of enterprise management [2]. But at present, some enterprises have not work in this field, lead to enterprise management in the "line" and "offline" aspects of the combination of relatively weak, in particular, some enterprises have no deep understanding to "Internet Accelerated Speed Era" the significant influence to the enterprise management, the implementation of "Internet Accelerated Speed Era enterprise management model" is relatively weak, especially in enterprise management platform terminal construction is relatively lag, has not yet been anywhere at any time using the Internet to achieve the purpose of the enterprise management. Some enterprises do not pay attention to the construction of "cloud platform" for enterprise management, and lack of effectiveness in the development, construction and management of "cloud platform". As a result, there is no field of enterprise management and no expansion, relatively few contents of enterprise management, and the enterprise management objectives are not diversified enough. As some enterprise management platform system construction is not in place, this requires enterprises must make great efforts to build enterprise management platform.

\section{B. The resource system is not perfect}

The Internet age has created good conditions for enterprise management innovation, especially because of the powerful information technology, network technology, big data technology and cloud technology in the Internet age, which can realize the scientific allocation of enterprise resources. However, at present, some enterprises have not been in the construction of comprehensive, all-staff, whole-process resource system efforts, so it is not conducive to the in-depth development of enterprise management. For example, some enterprises in the process of carry out the work of management, the lack of effective application of the technology of data, and various departments to carry out the management work of collaborative and mutual coordination between is not reach the designated position, lead to the integrity of the enterprise management is not strong, the Marketing Department, finance department, administration department, hr department and other departments have not using Internet technology to establish a resource sharing system of interconnectivity characteristics, which restricted the in-depth development of enterprise management. Some enterprises lack the ability to use Internet technology to strengthen the integration of enterprise resources. Although some enterprises have built ERP systems, the tightness between various modules is not high and the efficiency of enterprise management is not strong, which is also not conducive to the in-depth development of enterprise management.

\section{Lack of innovative talents in the new era.}

As the foundation of enterprise development, talent reserve is also the key to enterprise future development and progress. In all aspects of enterprise management, talent support is the main factor to improve enterprise management system. Moreover, many enterprises to save costs and ignore the cultivation of innovative talents, on the introduction of innovative talents and exists the phenomenon of half-heartedly, at the same time, each have different support to the enterprise in our country, and unconscious to introduce innovative talents in large state-owned enterprises, small and medium enterprises to introduce innovative talents, causing the waste of human resources in the market, also can not guarantee the quality of enterprise management innovation, enterprise environment orderly development for the future.

\section{Enterprise management marketing model lags behind}

In the past, the traditional marketing modes are mainly dealers, agents and direct sales. In the period when the information is not developed, these three marketing modes are the main ways for enterprises to sell products. And with the development of information technology, especially in today's era of information explosion, the traditional marketing model has obvious hysteresis, product production, face not dock with the customers in time, after-sales service can't quickly to meet customer demand, reduce the customer's consumption experience and expectations of future enterprise products. However, under the new era of marketing model is also faced with many problems, such as due to the information authenticity, the customer can't independently determine whether the enterprise to provide true information, or for example because of the huge amount of information, most belong to spam, the customer can't filter out the information and cause the loss of useful information. All these problems are important reasons for enterprises to resist the marketing innovation mode in the new era. 


\section{IMPLEMENTATION STRATEGY OF ENTERPRISE MANAGEMENT INNOVATION IN THE ERA OF "INTERNET ACCELERATED SPEED ERA"}

\section{A. We will improve the enterprise management platform system}

In order to do a good job in enterprise management in the Internet era, breakthroughs must be made in building a more scientific and perfect platform system to lay a foundation for promoting enterprise management reform and innovation. Therefore, in addition to establishing specialized enterprise management platforms, enterprises should pay more attention to the interconnection and interworking of enterprise management terminals, strengthen the access of computers, mobile phones, tablets and other terminals, constantly expand the application fields of enterprise management platforms, and realize the purpose of enterprise management anytime and anywhere [3]. Enterprise in the process of perfecting the enterprise management platform, even more pay great attention to enterprise strategic and fusion of the platform, such as in the process of enterprise management, to further strengthen the coordination function of enterprise management and organization function, to investigate the basic situation of enterprise management and analysis, find out the weak links of the existence of, and use of the Internet technology was improved, make the enterprise management platform can play a positive role in key areas and key parts. In the process of improving the enterprise management platform system, it is necessary to strengthen the input in all aspects. Enterprises should, according to their own development reality, start from the enterprise management reform, increase the input year by year, and build an enterprise management platform with network characteristics through several years of efforts.

\section{B. We will improve the enterprise management resource system}

With the more and more popular modern enterprise management concept, strengthen the integration and effective application of enterprise resources, pay attention to improve the strategic enterprise management, enterprises can use the Internet to build a more scientific and complete resource system, so as to achieve the extraordinary and leap-forward development of enterprise management. This requires enterprises to learn to use the "Internet Accelerated Speed Era" thinking to carry out enterprise management in the process of carrying out enterprise management, so that enterprise management can penetrate into all fields and levels, and strengthen the comprehensive functions of enterprise management through effective resource management [4]. For example, enterprises should give full play to the positive role of all departments, effectively allocate enterprise resources with big data technology and cloud computing technology, and strengthen the efficiency of enterprise resources. For another example, enterprises can establish strategic cooperative relations through the Internet to jointly carry out enterprise management, and meanwhile realize the sharing of enterprise resources. In the process of perfecting the enterprise resource management system, enterprise even more pay great attention to cooperate with the strategy of "third party", such as the enterprise can make use of the Internet technology, cloud technology development "cloud" accounting platform, is beneficial to decrease the cost of financial management, both at the same time can also make the enterprise financial management is more specialized and systematic, and integration with external resources.

\section{We will actively introduce innovative talent and increase personnel training}

Enterprises should actively introduce innovative talents under existing policies. In the era of "Internet plus", it is more important to actively cultivate and introduce innovative technical talents, and strengthen the management of innovative talents with Internet technology. Through Internet recruitment and other means, enterprises can accelerate the updating of their talent reserve and reduce the cost of talent introduction. At the same time, enterprises should also pay attention to the cultivation of internal talents. Learning activities can be carried out on a regular basis, and regular skills tests can be conducted by using Internet technology, which can maintain the vitality of relevant professional talents. Talent cultivation is the key for enterprises to maintain vitality. Enterprises should adapt to the development requirements of the new era, encourage the development of technical talents, and improve the core competitiveness of enterprises in the future.

\section{Rational use of Internet technology to speed up the transformation of enterprise marketing model}

The development of Internet era is a double-edged sword for society and enterprises. On the one hand, Internet technology can bring more economic benefits to enterprises and provide new impetus and support for their development. On the other hand, Internet technology also brings a lot of negative impacts to enterprises. For example, the publication of false information on the Internet makes it impossible for buyers to distinguish the authenticity of information, which, to some extent, will have a lot of negative impacts on related enterprises and increase the sales risk of enterprises. Therefore, enterprises should make reasonable use of Internet technology, take its essence, take its dregs. In addition, enterprises should be good at using digital information means to change the traditional marketing mode and use network information to serve their product sales. At the same time, enterprises should also improve their after-sales service, timely deal with product sales problems, give feedback to customers, and improve customer group consumption experience [5].

\section{CONCLUSION}

To promote the development of the enterprise management innovation, enable it to adapt to the needs of the development of the era of "Internet Accelerated Speed Era" enterprises should fully realize the importance of "Internet Accelerated Speed Era" to the enterprise management innovation, timely innovation enterprise management concept, implementing flating management mode, innovative human resource management, realize the goal of enterprise management refinement and reasonable configuration enterprise resources and adopt digital marketing and innovation, through various ways to improve enterprise management level, build a good foundation for the long-term development of the enterprise. 


\section{REFERENCES}

[1] Li yuanyuan. Research on " Internet Accelerated Speed Era "and modern enterprise human resource management innovation [J]. Think tank era,2019(29):30+34

[2] Lin yueqi. Research on management innovation of small and medium-sized enterprises under the background of " Internet Accelerated Speed Era " [J]. Business economics,2019(06):124-125.

[3] Anthonyliu. Introduction to " Internet Accelerated Speed Era " in the era of enterprise management innovation [J]. Journal of management informationization in China, 2019, 22 (12) : 62-63.

[4] Liu bingwei. Analysis of innovation path of enterprise strategic management based on the background of " Internet Accelerated Speed Era" $[\mathrm{J}]$. Sme management and technology (current issue),2019(05):25-26

[5] Xin pingping, ma dongrun. Discussion on enterprise management innovation strategy in the era of " Internet Accelerated Speed Era " [J]. Modern marketing (xunxin),2019(05):147. 